\title{
ABH Secretor Status of the Fetus: a Genetic Marker Identifiable by Amniocentesis
}

\author{
PETER HARPER, WILMA B. BIAS, JUDITH R. HUTCHINSON, and \\ VICTOR A. MCKUSICK \\ From the Division of Medical Genetics, Fohns Hopkins University School of Medicine and
fohns Hopkins Hospital, Baltimore, USA
}

The increasing use of amniocentesis, together with an expanding knowledge of the human chromosome map, has made the subject of genetic linkage in man one that is no longer of only academic interest. Given a close linkage of the locus of a particular disease with that for a marker trait detectable in utero, it should be possible to predict which pregnancies in a given family would be likely to be affected, and in the case of severe disease this information might permit parents to achieve healthy families through the selective termination of affected pregnancies (Edwards, 1956; Renwick, 1969a).

The ability to detect genetic markers in early fetal life is thus of considerable potential importance, although, being essentially indirect, the linkage approach to antenatal diagnosis has two inherent limitations. Firstly, a prediction would not be possible in every case, since in a variable proportion of families, depending on gene frequencies and ability to detect the heterozygous state, the linkage data would be uninformative. Secondly, the possibility of crossing over means that only close linkages can be utilized. Nevertheless, this method may well extend the scope of antenatal diagnosis to areas where it is at present not feasible by more direct means.

The present study was performed to test whether the locus controlling secretion of the ABH blood group substances into body fluids can reliably be identified in amniotic fluid during early pregnancy. It forms part of a wider investigation of the linkage relationship of the secretor locus with that for myotonic muscular dystrophy, and its application in antenatal diagnosis.

\section{Methods}

Sixty-seven women undergoing termination of pregnancy at the Johns Hopkins Hospital were studied. The

Received 7 April 1971. indication for termination was the mental health of the mother in all but 3 of the patients; in only one instance was there any suspected abnormality of the fetus. The duration of pregnancy, as determined from the date of last mentrual period, ranged from 9-24 weeks with a mean of 17 weeks; $52 \%$ of the women were white and $48 \%$ negro; there was one twin pregnancy.

Samples of amniotic fluid were obtained either by amniocentesis immediately before saline injection, or, in cases where hysterectomy or hysterotomy were being performed, by aspiration of fluid under direct vision. In these latter cases cord blood was taken, also under direct vision, so that the chance of contamination of amniotic fluid or fetal blood was minimized. Samples were collected under sterile conditions, the amniotic fluid being frozen at $-20^{\circ} \mathrm{C}$ until analysed, while fetaf blood was refrigerated at $4^{\circ} \mathrm{C}$ in acid-citrate-dextrosesolution.

The maternal ABO blood group was recorded and maternal saliva was collected for analysis for ABH substances by the semi-quantitative agglutination inhibition method; results were graded from 0 to 4 + agglutination for serial dilutions of saliva.

Amniotic fluid samples were examined for the presence of $A, B$, and $H$ substances, after removal of cellular deposit by centrifuging. The method used was similar to that for saliva, but undiluted amniotic fluid was used with serial dilutions of antibody from 1 in 6 to 1 in 16 . The analyses were performed without knowledge of the maternal secretor type or blood group or of the fetal blood group.

Inconsistencies in typing of the amniotic fluid were few, and repeat analysis gave identical results. In only one of the 68 samples, a weak B secretor, was there any doubt in the classification. The presence or concentration of substances could not be related to length of gestation or to race.

\section{Results}

Soluble ABH blood group substances were found in $54(79.4 \%)$ of the 68 samples of amniotic fluid studied. This proportion is similar to the proportion of secretors in the general population as 
determined by saliva in several large published series (Table I), there being little variation between different ethnic groups.

TABLE I

PROPORTION OF AMNIOTIC FLUID SAMPLES CONTAINING SOLUBLE ABH SUBSTANCES COMPARED WITH PROPORTION OF SECRETORS IN VARIOUS POPULATIONS

\begin{tabular}{l|r|r|r}
\hline \multicolumn{1}{c|}{ Source } & Total & Secretor & $\begin{array}{c}\text { Secretor } \\
\left({ }^{\circ}{ }_{0}\right)\end{array}$ \\
\hline \begin{tabular}{l|r|r} 
Ammiotic fluid \\
Present series
\end{tabular} & 68 & 54 & $79 \cdot 4$ \\
\hline Saliva & & & \\
Doll et al (1961), London & 385 & 303 & $78 \cdot 7$ \\
Ball (1962), Ibadan & 300 & 224 & $74 \cdot 7$ \\
Newman et al (1961), Iowa & 1261 & 951 & $75 \cdot 4$ \\
McConnell (1966), Liverpool & 2435 & 1845 & $75 \cdot 7$ \\
\hline
\end{tabular}

To test whether the presence of blood group substances in the amniotic fluid reflected maternal secretor status, the results of amniotic fluid analysis were compared with those from maternal saliva. Table II shows that there is no close correlation, the distribution of results being similar to that expected

TABLE II

AMNIOTIC FLUID AND MATERNAL SECRETOR STATUS

\begin{tabular}{l|c|c|c}
\hline & \multicolumn{2}{|c|}{ Maternal Saliva } & \multirow{2}{*}{ Total } \\
\cline { 2 - 3 } & Secretor & Non-secretor & \\
\hline \begin{tabular}{c|c} 
Amniotic fluid \\
'Secretor'
\end{tabular} & $\begin{array}{c}26(24 \cdot 4)^{*} \\
5(6 \cdot 6)\end{array}$ & $\begin{array}{c}8(9 \cdot 8) \\
3(2 \cdot 6)\end{array}$ & $\begin{array}{r}34 \\
8\end{array}$ \\
\hline 'Non-secretor' & 31 & 11 & 42 \\
\hline Total & 31 & \\
\hline
\end{tabular}

* Numbers in parentheses are those expected on chance alone.

by chance alone. Likewise, there is no close correlation between the type of blood group substance found in the amniotic fluid and the blood group of the mother, although the overall proportions are moderately similar in the two groups (Table III).

TABLE III

AMNIOTIC FLUID AND MATERNAL BLOOD GROUP

\begin{tabular}{c|c|c}
\hline & Amniotic Fluid & Maternal Blood \\
\hline $\mathrm{A}$ & $17(31.5 \% \mathrm{o})$ & $30\left(46.2{ }^{\circ}\right)$ \\
$\mathrm{B}$ & $10(18.5 \% \mathrm{o})$ & $8(12.3 \% \%)$ \\
$\mathrm{AB}$ & $1(1.9 \%)$ & $1(1.5 \%)$ \\
$\mathrm{O}$ & $26(48.1 \%)$ & $26(40.0 \%)$ \\
\hline Total & 54 & 65 \\
\hline
\end{tabular}

ABO type concordant-26. ABO type discordant-25.

When the type of substance in the amniotic fluid is compared with the fetal blood group, however, close correlation is seen. Eighteen out of the 19 samples in which $\mathrm{ABH}$ substances were present agreed with the fetal blood group; the single remaining sample, which agreed with the maternal blood group (A) rather than fetal blood group (O), was found to be contaminated by maternal blood. It was the only sample so contaminated, and the maternal origin of the blood was confirmed by haemoglobin electrophoresis.

TABLE IV

\begin{tabular}{lr} 
AMNIOTIC FLUID AND FETAL BLOOD \\
GROUP \\
\hline Total samples with fetal blood group available & 23 \\
Amniotic fluid containing ABH substances & 19 \\
Concordant with fetal blood group & 18 \\
Discordant with fetal blood group & 1
\end{tabular}

\section{Discussion}

The detection of soluble ABH blood group antigens in amniotic fluid has received little attention in comparison with the extensive work on $\mathrm{ABO}$ and $\mathrm{Rh}$ antibodies, and such work as has been done has been confined to amniotic fluid from term deliveries. Studies by Putkonen (1930) showed that ABH substances were present in 20 out of 30 samples, and agreed with the serotype of the infant rather than of the mother. In 20 full-term deliveries, Freda (1958) found that $A B H$ substances were present only when the infant was a secretor, but that they could be found in fetal membranes when the mother, not the infant, was a secretor. In neither of these studies was the fluid centrifuged to remove cells, an important point in view of the clear demonstration that amniotic fluid cells carry the ABH antigens (Scott, Coulsen, and Goulden, 1969). Two further; series (Przestwor 1964, Turowska and Bromboszcz, 1967) have also shown that the occurrence of $\mathrm{ABH}$ antigens in full term amniotic fluid correlates with fetal secretor type.

While it seems clear from the above work that the secretor status of the fetus at full term can be accurately determined from amniotic fluid, this cannot be assumed to be true for early pregnancy, since fetal saliva might be expected to be present in full-term fluid and in part or entirely determine the results.

The present data, however, provide evidence that $\mathrm{ABH}$ substances are in fact secreted into amniotic fluid at an early stage of pregnancy, and that they are of fetal, not maternal origin. In no case (apart from the single instance due to contamination with maternal blood) was there disagreement between fetal blood group and the type of substance present 
in amniotic fluid, whereas there was no correlation between the fluid and maternal blood group or maternal secretor status. In addition, the proportion of amniotic fluid samples containing $\mathrm{ABH}$ antigens was similar to the proportion of secretors in the population. The direct proof of correlation between amniotic fluid and fetal secretor type was inevitably lacking in this study; an analysis of amniotic fluid samples from pregnancies which have been allowed to proceed to term after amniocentesis is in progress.

It thus seems likely that the secretor status of the fetus can be used as a genetic marker in amniotic fluid, although further work will be required to determine the margin of error involved in the procedure. The suspicion that the locus for the disease myotonic muscular dystrophy is linked with the secretor locus (Mohr, 1954), which is at present under further investigation, gives practical importance to the ability to detect fetal secretor status, with regard to making an antenatal prediction. In addition the detection of soluble blood group substances provides a simple method of determining fetal $\mathrm{ABO}$ blood group in the $70-80 \%$ of individuals that are secretors, and can serve as a useful check on the blood group as determined from the amniotic fluid cells. The only disease known definitely to be linked to the ABO locus is the nail-patella syndrome (Renwick, 1969b), but in the future, other more serious conditions showing such linkage may well be discovered in which antenatal diagnosis would be of practical importance.
We are grateful to members of the department of Obstetrics and Gynecology, Johns Hopkins Hospital, in particular, Dr Marguerite Shepard and Dr John Tyson, for their assistance in this study. One of us (P.H.) is a recipient of a Muscular Dystrophy Associations of America research fellowship. Dr J. H. Renwick made valuable suggestions.

\section{REFERENCES}

Ball, P. A. J. (1962). Influence of the secretor and Lewis genes on susceptibility to duodenal ulcer. British Medical fournal, 2, 948950.

Doll, R., Drane, H., and Newall, A. C. (1961). Secretion of blood group substances in duodenal, gastric and stomal ulcer, gastric carcinoma, and diabetes mellitur. Gut, 2, 352-359.

Edwards, J. H. (1956). Antenatal detection of hereditary disorders. Lancet, 2, 579.

Freda, V. J. (1958). ABO (H) blood group substances in the human maternal fetal barrier and amniotic fluid. American Fournal of Obstetrics and Gynecology, 76, 407-416.

McConnell, R. B. (1966). The Genetics of Gastro-intestinal Disorders. Oxford University Press, London.

Mohr, J. (1954). A study of linkage in man. (Opera ex Domo Biologicae Hereditariae Humanae Universitas Hafniensis, Vol. 33.) Munksgaard, Copenhagen.

Newman, E., Naifeh, G. S., Auer, J. E., and Buckwalter, J. A (1961). Secretion of ABH antigens in peptic ulceration and gastric carcinoma. British Medical fournal, 1, 92-94.

Przestwor, E. (1964). Distribution of ABH group substances in amniotic fluid. Poznanski Towarzystwo Przjaciol Nauk, 29, 197216.

Putkonen, T. (1930). Gruppenspezifischen Eigenschaften verschiedener Körperflüssigkeiten. Acta Societatis Medicorum Fennicae 'Duodecim', 14, 82-87.

Renwick, J. H. (1969a). Widening the scope of antenatal diagnosis. Lancet, 2, 386.

Renwick, J. H. (1969b). Progress in mapping human autosomes British Medical Bulletin, 25, 65-73.

Scott, J. S., Coulson, A., and Goulden, R. (1969). Antenatat determination of fetal blood groups. Fournal of Obstetrics and Gynaecology of the British Commonwealth, 76, 330-332.

Turowska, B. and Bromboszcz, A. (1967). ABO group substances in the amniotic fluid. Przeglad Lekarski, 23, 731-733. 